\title{
Views of community pharmacists in Lebanon on the unified prescription: a mixed method study
}

Hani Dimassi, ${ }^{1}$ Aline Bou Maroun, ${ }^{2}$ Marguerita Saadeh, ${ }^{3}$ Joanne Khabsa, ${ }^{2}$ Jessica-Lynn Abdou ${ }^{2}$ and Shadi Saleh ${ }^{4}$

${ }^{1}$ Department of Pharmaceutical Sciences, School of Pharmacy, Lebanese American University, Byblos, Lebanon. ${ }^{2}$ Department of Pharmacy Practice, School of Pharmacy, Lebanese American University, Byblos, Lebanon. ${ }^{3}$ Karolinska Institutet and Stockholm University, Stockholm, Sweden. ${ }^{4}$ Department of Health Management and Policy, American University of Beirut, Beirut, Lebanon. (Correspondence to: Hani Dimassi: hani.dimassi@lau.edu.lb).

\begin{abstract}
Background: The unified prescription was introduced in Lebanon in 2011; an aim was to save on medication expenditure. Aims: The aim of this study was to evaluate the views of community pharmacists on the effect and usefulness of the unified prescription.
\end{abstract}

Methods: A cross-sectional telephone survey of community pharmacists from all governorates of Lebanon was conducted. A questionnaire was used to collect demographic data, pharmacists' views on the effect of the unified prescription on their work, the percentage of prescriptions in which the prescriber had indicated that the medicine should not be substituted with a generic equivalent and the percentage needing clarification from the prescriber. Face-to-face interviews were held with 12 pharmacists to explore their views further.

Results: Of 251 pharmacists interviewed, 56.8\% did not think the unified prescription was useful, $34.8 \%$ thought it complicated their work and $24.0 \%$ that it reduced their autonomy. The in-depth interviews showed that autonomy was perceived to be restricted because of the difficulty in convincing patients to accept a substitute generic medicine, which the unified prescription allowed. The unified prescription complicated pharmacists' work because of increased paperwork and the need for more storage. Pharmacists felt that the large number of prescriptions in which the prescriber had indicated that the medicine should not be substituted undermined the purpose of the unified prescription.

Conclusion: The implementation of the unified prescription was not considered a success by community pharmacists in Lebanon. Efforts are needed to improve communication with prescribers and educate the public about pharmacists' role and generic medicines.

Keywords: pharmacists, prescriptions, drugs, generics, Lebanon

Citation: Dimassi H; Maroun AB; Saadeh M; Khabsa J; Abdou J; Saleh S. Views of community pharmacists in Lebanon on the unified prescription: a mixed method study. East Mediterr Health J. 2020;26(12):1539-1547. https://doi.org/10.26719/emhj.20.127

Received: 30/10/19; accepted: 15/03/20

Copyright (c) World Health Organization (WHO) 2020. Some rights reserved. This work is available under the CC BY-NC-SA 3.0 IGO license (https:// creativecommons.org/licenses/by-nc-sa/3.o/igo).

\section{Introduction}

In 2011, a new unified prescription was introduced in Lebanon, as a result of which the pharmacy profession had to make some substantial changes to their practices. This new policy was designed to improve health care services, in which pharmacists play an important role; however, no studies have evaluated the effect of the unified prescription on the daily practice of community pharmacists and whether they were able to adapt to the changes.

The triplicate prescription form was instated by ministerial decision no. 1925 issued by the Lebanese government in 2011. This decision introduced the unified prescription form with three copies: white for the patient, pink for the pharmacist and yellow for the physician. Its objective differed from that of the triplicate prescription programme in North America.

Triplicate prescription forms have been used in the United States of America (USA), Canada and other countries to monitor certain drugs with high potential for abuse. For instance, in 1989, New York State mandated triplicate prescription for benzodiazepines
$(1,2)$. The triplicate prescription allows the monitoring of prescribing practices, provides feedback on targeted drugs and identifies areas of misuse (3).

The Lebanese government's intention with the unified prescription programme was to reduce medication costs by increasing the use of cheaper generic medicines. The programme would empower pharmacists to suggest substitution to their clientele who were presenting prescriptions to be filled (4). Relieving the burden on public finances is essential, particularly as expenditure on prescription drugs in Lebanon is estimated to rise to US\$ 2.71 billion in 2020 , accounting for $52 \%$ of total health expenditure (4).

With generic substitution at the core of the unified prescription programme, pharmacists are supposed to play a key role in addressing patients' enquiries about generic drugs and correcting any misconceptions on their effectiveness and value $(5,6)$. The usually lower cost of generic medicines is often mistakenly interpreted as inferiority of these medicines compared with proprietary medicines with known brand names. This obstacle for substitution is more obvious with lower educational 
level and socioeconomic status of patients (7-9). As such, pharmacists are in a unique position to educate patients about bioequivalence studies and good manufacturing practices that generic medicines undergo to overcome any mistrust patients may have about accepting drug substitution $(9,10)$.

The implementation of the unified prescription was expected to affect the physician-pharmacist-patient relationship, especially the pharmacists who are the link between the prescriber, the patient and the medication. Therefore, the aim of our study was to evaluate the views of community pharmacists on the newly implemented unified prescription in terms of its usefulness and its effect on their workflow - its complexity and their autonomy. Pharmacists' autonomy is their ability to do their jobs independently without having to refer to physicians for drug substitutions, and to make and implement decisions for the benefit of the patient.

\section{Methods}

\section{Design and sample}

This was a mixed-method study: the first part (phase 1, June-August 2016) was a quantitative survey and the second part was qualitative interviews (phase 2, April 2017). Phase 1 was a national cross-sectional survey of community pharmacists working in Lebanon. A complete list of these pharmacists was extracted from the directory of the Order of Pharmacists of Lebanon, which included also the pharmacy's name, telephone number and address. The list was stratified by the six Lebanese governorates and a stratified random sample proportionate to size was selected. The targeted sample size was 300 pharmacists based on a $95 \%$ confidence interval with $5-6 \%$ precision. To reach the target sample size of 300 , we attempted to contact 463 pharmacists, of whom 161 either declined to participate, the telephone number was wrong, or there was no answer, giving a response rate to $65.2 \%$. Furthermore, we excluded 51 participants because they did not hold a pharmacy degree, so the final sample size was 251. Phase 2 was an in-depth face-to-face interview with 12 pharmacists from the six governorates, representing both sexes and employment status (owner versus employee). This sample proved to be sufficient as data saturation was reached (11).

\section{Questionnaire}

The questionnaire included different sections: demographic data of the pharmacists, views of the unified prescription. The demographic section included questions about age, sex, years of experience, degree (BSc in pharmacy versus PharmD) and ownership of the pharmacy (versus employee) (independent variables). The unified prescription section asked three questions: was the unified prescription useful, did it affect work autonomy and did it affect the workflow (did it make it more complicated or simpler). The last section were questions about the percentage of prescriptions: (i) in which the prescriber had indicated that no substitution of the prescribed medicine should be made by the pharmacist and (ii) that required an intervention from the pharmacist. We developed the questionnaire in English and two independent professional translators translated it into Arabic and then back-translated it for validation; there were no major discrepancies between the translators. Finally, we pilot-tested the questionnaire on community pharmacists who were not included in the final sample for clarity and appropriateness of questions, as well as the length of the interview.

The in-depth interview was based on three areas of discussion: (i) How do you define autonomy in your pharmacy practice?; (ii) How did the new unified prescription affect your work?; and (iii) How useful has the unified prescription been?

\section{Data collection}

Two pharmacy graduates collected the data for phase 1 over the phone. They were trained on how to remain objective, how to probe and how to prevent divergence from the questions. All respondents gave verbal consent to participate. In case of refusal or a wrong number, we randomly selected a replacement from the same governorate. We gave the respondents the option to be called later at a more convenient time.

In the second phase, all 12 pharmacists who participated in the face-to-face in-depth interview provided their consent. We interviewed these pharmacists at their pharmacies. The interviews were audio-recorded and tapes were reviewed for data analysis and theme identification.

\section{Data analysis}

The interviewers used Excel for data entry of the data collected during the telephone survey using a coding scheme. The final data entry sheet was imported to SPSS, version 24 (12). We used frequencies and percentages to summarize categorical variables, and means and standard deviations (SD) to summarize numerical variables. We used the Pearson chi-squared test and the ANOVA $F$ test to assess differences in proportions and means, respectively. We set the level of significant at $P \leq 0.05$.

We reviewed and analysed the audio recordings and notes taken during the face-to-face interview to identify the themes that emerged.

\section{Ethical considerations}

This study was approved by the Institutional Review Board of the Lebanese American University (LAU.SOP. HD2.0/Jul/2016), and amended for face-to-face interviews (LAU.SOP.HD2.5/Jul/2016). Oral consent was obtained from the participants for the telephone and the face-to fact interviews.

\section{Results}

\section{Results from the telephone survey}

The sample represented all six Lebanese governorates with a distribution that closely matched the distribution of community pharmacies in the country. Males (51.8\%) 
and females (48.2\%) were almost equally represented and the biggest proportion were aged 30-39 years (35.2\%). Most of the pharmacist had a bachelor of science degree (61.4\%) compared with $38.6 \%$ with a degree in pharmacy, $80.1 \%$ were pharmacy owners and $74.8 \%$ had more than 6 years of experience (Table 1).

More than half of the pharmacists (56.8\%) did not think that the unified prescription was useful, and $48.8 \%$ did not think it had affected their workflow (neither simplifying nor complicating it) and $63.2 \%$ did not think it had affected their autonomy. Nonetheless, of the remaining 128 pharmacists, most perceived a negative impact: $68 \%$ of the 128 reported that the unified prescription complicated their work (rather than simplified it), and $65 \%$ reported that it reduced their autonomy (rather than increased it).

Pharmacists reported an average of 59.8\% (median $70 \%$ ) of prescriptions were labelled with no substitution by the prescribing physician. Furthermore, they reported an average of $23.7 \%$ prescriptions needed further clarification from the prescribing physician, mostly because of unclear handwriting (92.4\%), followed by wrong dose (45.0\%) (Table 2).

Responses to the three unified prescription questions were statistically associated. Pharmacists who perceived the unified prescription to be useful, compared to not useful, were more likely to report that unified prescription simplified their work $(36.4 \%$ versus $1.4 \%$, $P<0.001)$, and increased their autonomy $(23.4 \%$ versus $4.9 \%, P<0.001$ ) (Table 3). In addition, those claiming that unified prescription increased their autonomy were more likely to report it simplified their work as well $(56.3 \%$ versus $10.0 \%$ among those that reported less autonomy, $\mathrm{P}<0.001$; Table 4).

Results of a bivariate analysis comparing responses to the three questions on the unified prescription across the independent variables in the study failed to detect any significant differences, indicating that the pharmacists' answers to the unified prescription questions were uniform across their socioeconomic backgrounds. Therefore, we decided to carry out in-depth interviews with a group of pharmacists to further understand their viewpoint.

\section{Results of the qualitative analysis}

When we asked the pharmacists interviewed about how they defined work autonomy, they pointed to the ability to do their jobs independently, without having to refer to physicians for drug substitutions, and the ability to make and implement decisions for the benefit of the patient. When we asked how their autonomy was linked to the unified prescription, most pharmacists said that it did not add to their autonomy. "Autonomy was restricted by unified prescription, either because of no substitution use or because generics are more expensive than brands" (male, Mount Lebanon, owner). In fact, most of the pharmacists we interviewed brought up the lack of an adequate pricing strategy. They reported that the price of brand medications had decreased substantially over

\begin{tabular}{|c|c|c|}
\hline \multicolumn{3}{|c|}{ Table 1 Characteristics of community pharmacists, Lebanon } \\
\hline Characteristic & $\begin{array}{c}\text { No. } \\
(n=251)\end{array}$ & $\%$ \\
\hline \multicolumn{3}{|l|}{ Governorate } \\
\hline Beirut & 26 & 10.4 \\
\hline Bekaa & 35 & 13.9 \\
\hline Mount Lebanon & 122 & 48.6 \\
\hline Nabatieh & 13 & 5.2 \\
\hline North & 33 & 13.1 \\
\hline South & 22 & 8.8 \\
\hline \multicolumn{3}{|l|}{ Sex } \\
\hline Male & 130 & 51.8 \\
\hline Female & 121 & 48.2 \\
\hline \multicolumn{3}{|l|}{ Age group (years) } \\
\hline $20-29$ & 62 & 25.1 \\
\hline $30-39$ & 87 & 35.2 \\
\hline $40-49$ & 57 & 23.1 \\
\hline $50-77$ & 41 & 16.6 \\
\hline Missing & 4 & \\
\hline \multicolumn{3}{|l|}{ Degree } \\
\hline BSc in pharmacy & 154 & 61.4 \\
\hline PharmD & 97 & 38.6 \\
\hline \multicolumn{3}{|l|}{ Position } \\
\hline Pharmacy owner & 201 & 80.1 \\
\hline Pharmacy employee & 50 & 19.9 \\
\hline \multicolumn{3}{|l|}{ Years of experience } \\
\hline$\leq 5$ & 63 & $25 \cdot 3$ \\
\hline $6-15$ & 96 & 38.6 \\
\hline$\geq 16$ & 90 & 36.1 \\
\hline Missing & 2 & \\
\hline
\end{tabular}

the previous year, making generic substitution no longer meaningful. As one pharmacist explained: "Unified prescription was meant to decrease costs through generic substitution; whereas currently, some generics are more expensive than brands" (female, Beirut, employee). On the other hand, a few pharmacists thought that the unified prescription added to their autonomy: "Unified prescription provided autonomy by giving us the ability and authorization to substitute brand for generic" (male, Mount Lebanon, owner). Another pharmacist described the actual situation: "Theoretically, the unified prescription was supposed to give more autonomy to pharmacists, however, it did not, since the list of substitutes is not clear nor readily accessible, and doctors are using 'no substitution' excessively" (female, North, owner). A female pharmacy owner in South governorate raised a concern shared by other pharmacists: "When no substitution is not recorded on the prescription, we have trouble convincing patients of the substitution without calling the physician. They obviously trust their doctors much more than they trust us." 


\begin{tabular}{|c|c|c|}
\hline Question & No. $(n=250)$ & $\%$ \\
\hline \multicolumn{3}{|l|}{ Is the unified prescription helpful? } \\
\hline Yes & 108 & 43.2 \\
\hline No & 142 & 56.8 \\
\hline Missing & 1 & \\
\hline \multicolumn{3}{|c|}{ Did the unified prescription simplify or complicate your work? } \\
\hline Simplified & 41 & 16.4 \\
\hline Complicated & 87 & 34.8 \\
\hline No change & 122 & 48.8 \\
\hline Missing & 1 & \\
\hline \multicolumn{3}{|c|}{ How did the unified prescription affect your autonomy? } \\
\hline Less autonomy & 60 & 24.0 \\
\hline More autonomy & 32 & 12.8 \\
\hline Did not change & 158 & 63.2 \\
\hline Missing & 1 & \\
\hline Percent of prescriptions: & Mean (SD) & Median (IQR) \\
\hline Labelled as non-substitutable ${ }^{\text {a }}$ & $59.8(28.2)$ & $70(38.7)$ \\
\hline Needed clarification from prescriber & $23.7(24.5)$ & $15(35.0)$ \\
\hline Problem encountered with prescriptions & No. $(n=251)$ & $\%$ \\
\hline Wrong dose & 113 & 45.0 \\
\hline Drug-drug interaction & 68 & 27.1 \\
\hline Wrong dosage form & 60 & 23.9 \\
\hline Drug-disease interaction & 53 & 21.1 \\
\hline Wrong drug & 47 & 18.7 \\
\hline Unclear handwriting & 232 & 92.4 \\
\hline
\end{tabular}

SD: standard deviation; IQR: interquartile range.

${ }^{a}$ The doctor indicates on the prescription that the brand medicine should not be replaced by the pharmacist with an equivalent generic medicine.

When we asked the pharmacists if the unified prescription had simplified or complicated their work, most complained that it complicated their daily tasks. It added to their paperwork and increased the storage space required. The pink copy of the prescription, which is to be kept at the pharmacy, is hard to read, of poor quality and the ink fades with time. As explained by one pharmacist: "The pink copy is worthless after a few months because the ink disappears" (male, Mount Lebanon, owner). "It is not clear how long we should keep the prescription forms, and they are taking significant storage space" (male, Mount Lebanon, owner), Another pharmacist said: "Pink copies are almost never stamped, and when it comes to prescriptions for controlled substances, we have to send the patient back to the doctor's office to have it stamped, otherwise, it is not valid for dispensing" (female, South, owner).

As for the usefulness of the unified prescription, the interviewees stated that, although the form used is professional, well divided and user-friendly, it is not of added value. They stated that doctors do not fully abide by the form. Pharmacists still receive old prescription forms, especially for non-Lebanese patients and patients without third-party coverage. One pharmacist stated: "We should dispense the drug despite the use of the old form, otherwise, we will lose customers" (female, Mount Lebanon, employee). Therefore, a commonly reported concern of pharmacists was reinforcing the use of the unified prescription among all physicians. Interviewees reported that a large number of prescriptions are marked with no substitution, even when the prescription is for a generic medicine, indicating that doctors may lack an understanding of the purpose of no substitution or are receiving remuneration from companies to write no substitution.

A shared idea among pharmacists was that: "Unified prescription could have been more useful if it involved a change in the health care strategy, introduction of a patient profile system and electronic prescribing" (male, Mount Lebanon, owner). However, one pharmacist was a little more optimistic: "Unified prescription is partially useful. We are on the right track, but it has to be part of a whole system change" (male, North, owner). Additional reported barriers to effective implementation of the unified prescription included lack of patient awareness about generic medicines and little trust in community pharmacists: "I have to call the physician so that he/ she convinces the patient of the proposed swap [to a generic medicine]" (female, Mount Lebanon, employee). Similarly, another pharmacist explained that he rarely 


\begin{tabular}{|c|c|c|c|c|c|}
\hline \multirow[t]{3}{*}{ Effect of unified prescription on: } & \multicolumn{4}{|c|}{ Unified prescription perceived as: } & \multirow[t]{3}{*}{ P-value } \\
\hline & \multicolumn{2}{|c|}{ Useful $(n=107)$} & \multicolumn{2}{|c|}{ Not useful $(n=142)$} & \\
\hline & No. & $\%$ & No. & $\%$ & \\
\hline Work & & & & & $<0.001$ \\
\hline Less complicated & 39 & 36.4 & 2 & 1.4 & \\
\hline More complicated & 21 & 19.6 & 65 & 45.8 & \\
\hline No change & 47 & 43.9 & 75 & 52.8 & \\
\hline Autonomy & & & & & $<0.001$ \\
\hline Less autonomy & 27 & 25.2 & 33 & 23.2 & \\
\hline More autonomy & 25 & 23.4 & 7 & 4.9 & \\
\hline No change & 55 & 51.4 & 102 & 71.8 & \\
\hline
\end{tabular}

bothers to offer a substitute: "It is a waste of energy to try to explain to the patient that I am only offering an equivalent drug. I have had several patients who came back after purchasing the generic to exchange it for the initially prescribed drug" (male, Mount Lebanon, owner). Other pharmacists commented: "A whole population attitude needs to be changed through education, including education about the role of the pharmacist" (male, Mount Lebanon, owner), and "We are not allowed to exert our role as drug experts, and that needs a national awareness campaign" (female, Beirut, employee).

\section{Discussion}

In this study, we tried to examine the effect of introducing the new unified prescription, 5 years after its launch by the Lebanese government. In response to this new procedure, we found that the majority of Lebanese pharmacists had a negative opinion of the introduction of the unified prescription.

The new unified prescription form is available in three colour-coded copies: white for the patient (primarily for third party payer reimbursement), pink for the pharmacist (as a record of dispensing) and yellow for the physician (as proof of prescribing). The main difference from the previously used prescription form was the introduction of the generic substitution which allowed pharmacist to dispense an equivalent generic medicine rather than the proprietary branded one indicated by the doctor. Nonetheless the authority of the physician was maintained as he/she could select the non-substitutable medication option as per article 47 of the law of practice of pharmacy profession (13), which the pharmacist cannot override. However, implementation of the new form is still incomplete which may explain the mixed reactions of the community pharmacists surveyed. The main problems reported were related to generic substitution, unclear guidance on implementation of the new form and lack of public education about generic drugs and the role of a community pharmacist.

Generic medicines are often considered by health care professionals as inferior to their brand counterparts, mainly because of a sense of lack of compliance with the good manufacturing practices (14). Our findings that a large number of physicians frequently use the no substitution option concur with previous studies $(15,16)$. Possible explanations could be the poor trust of physicians in generic drugs as well as promotional incentives given to them by pharmaceutical companies. A review of physicians' perceptions on proprietary medicine concluded that the poor knowledge of physicians about biosimilar generic medicines was the main reason for such practice (17). A study in Jordan showed that 50$80 \%$ of physicians in Jordan were likely to oppose the replacement of brand drugs with generic substitutes (18). Another study from the United Arab Emirates showed that only $17 \%$ of patients were prescribed a generic drug and $56 \%$ received no background information from their physician about the availability of a generic medicine (19). Furthermore, a Danish study highlighted the importance of removing incentives to use branded drugs as a way to increase prescription of generic medicines (20). In spite of a documented surge in pricing of generic medicines across the world because, for example, drug shortages, supply disruptions and consolidations in the genericdrug industry, they are still the cheaper option $(21,22)$.

\begin{tabular}{|c|c|c|c|c|c|c|c|}
\hline \multirow[t]{2}{*}{ Effect on work complexity } & \multicolumn{2}{|c|}{ Less autonomy $(n=60)$} & \multicolumn{2}{|c|}{ More autonomy $(n=32)$} & \multicolumn{2}{|c|}{ No change $(n=157)$} & \multirow[t]{2}{*}{ P-value } \\
\hline & No. & $\%$ & No. & $\%$ & No. & $\%$ & \\
\hline Less complicated & 6 & 10.0 & 18 & 56.3 & 16 & 10.2 & $<0.001$ \\
\hline More complicated & 29 & 48.3 & 3 & 9.4 & 55 & 35.0 & \\
\hline No change & 25 & 41.7 & 11 & 34.4 & 86 & 54.8 & \\
\hline
\end{tabular}


In fact, decreasing the health care cost for both patients and governmental agencies was and remains the main objective of the unified prescription. However, a unique cost reduction policy that came into effect in Lebanon in 2015 (23) resulted in substantial decrease in the price of brand name medicines, which counteracted the financial benefit of many generic substitutions.

Pharmacists reported a collective sense that the execution of the unified prescription was ill-prepared, a finding supported by a 2017 study which reported a lack of adequate infrastructure and no clear direction on how to use the forms (16). Pharmacists were unsure of how long they should keep the pink copies or how they should file them while pointing out to the poor ink quality, a problem that has been previously raised (24). Moreover, physicians continue to use the old form, especially for uninsured or non-Lebanese patients, and pharmacists find themselves obliged to fill the prescription.

A study in Denmark listed a number of difficulties facing the implementation of a new prescription policy, including insufficient knowledge of physicians and uncertainty about procedures, unclear responsibilities, insufficient communication, clinician autonomy and low acceptance of the change (25). Pharmacists surveyed reported on average a 1-hour increase in workload per day, while most physicians stated that they did not fully understand all parts of the form. Overall, both pharmacists and physicians were dissatisfied with the new system (26).

Lebanese pharmacists believed that the unified prescription could have been more meaningful if it had been part of a larger national drug policy change. Such an initiative could include implementation of patient profiles, electronic pharmacy records and electronic prescribing, and a clear list of over-the-counter medicines. Studies confirm that electronic prescribing has a positive effect on the safety of prescribing practices (26) and can eliminate transcription errors (27). In theory, a modified prescription form that requires relevant medication information would reduce prescribing problems (28).

Pharmacists lacked the motive to dispense generic medicines because of poor incentives, lower profit and patients' resistance to change. According to a 2017 study, more than half of the Lebanese population is not aware of a definition of a generic drug and a larger proportion $(68 \%)$ is not sure of the pharmacological equivalency of the generic drug (15). Patients have constantly shown poor acceptance of substitution and insistence on the drug selected by the doctor. This is in contrast to the USA where the generic drug is widely prescribed (22), accounting for about $86 \%$ of all filled prescriptions (29).
The 2017 Lebanese study also supported the need for raising awareness about generic drugs among the public (15). For instance, discussing monetary concerns with patients might be a good start for the pharmacists to highlight the financial value of generics while correcting any common false beliefs that they may have about those drugs (10).

A different but related issue is the low public trust in community pharmacists. Pharmacists are the experts in medicines and their role extends far beyond dispensing; they frequently have to intervene to correct prescription errors (30). Educating and raising awareness among the public about the role that pharmacists in product selection is needed.

In light of these issues, we recommend that efforts are made by the government to raise awareness among the public that brand medicines can be changed for their generic equivalent and to help them understand that generic medicines are a cost-saving option with the same efficacy as their brand counterparts. The government should also work alongside pharmacists to highlight these issues and come up with solutions that will improve the unified prescription and support the role of pharmacists in providing the best patient care.

A limitation of our study is that it focused on how the unified prescription affected the work of pharmacists and overlooked the perspectives of patients and physicians. Taking account of the views of all involved parties on the prescription process could allow a better understanding of the issue at hand. Another limitation is the possibility of measurement bias. Perceptions and views are indirect measures and cannot substitute for direct measures. However, direct measurement of usefulness and workflow is hard to undertake.

Notwithstanding these limitations, our study used a mixed-method approach where the qualitative data along with the quantitative data provided a more comprehensive understanding of the issues with the unified prescription and a clearer insight of pharmacists' perceptions of this problem. Furthermore, to our knowledge, this is the first national study, whereby the results are representative of all Lebanese community pharmacists.

Funding: Lebanese American University - School of Pharmacy; grant number LAU SOP 2016-16. The funding body did not play any role in the study design, data collection or interpretation. The fund provided was used to pay interviewers' salaries.

Competing interests: None declared. 


\section{Points de vue des pharmaciens d'officine au Liban sur la prescription unifiée : une étude à méthodologie mixte}

\section{Résumé}

Contexte : La prescription unifiée a été introduite au Liban en 2011. L'objectif était d'économiser sur les dépenses de médicaments.

Objectifs : L'objectif de cette étude était d'évaluer le point de vue des pharmaciens d'officine sur l'effet et l'utilité de la prescription unifiée.

Méthodes : Une enquête téléphonique transversale a été menée auprès des pharmaciens d'officine issus de tous les gouvernorats du Liban. Un questionnaire a été utilisé pour recueillir des données démographiques, le point de vue des pharmaciens en ce qui concerne l'effet de la prescription unifiée sur leur travail. Il a également permis de recueillir le pourcentage de prescriptions pour lesquelles le prescripteur avait indiqué que le médicament ne devait pas être remplacé par un équivalent générique et le pourcentage nécessitant une clarification de la part du prescripteur. Des entretiens en face à face ont eu lieu avec 12 pharmaciens pour étudier leurs points de vue.

Résultats : Sur 251 pharmaciens interrogés, 56,8 \% ne pensaient pas que la prescription unifiée fût utile, 34,8\% trouvaient que cela compliquait leur travail et $24,0 \%$ estimaient qu'elle réduisait leur autonomie. Les entretiens approfondis ont montré que l'autonomie était considérée comme limitée en raison de la difficulté à convaincre les patients d'accepter un médicament générique de substitution, ce que la prescription unifiée permettait. Ce type de prescription a compliqué le travail des pharmaciens en raison des formalités accrues et de la nécessité de disposer de davantage de stockage. Les pharmaciens estimaient que le grand nombre de prescriptions dans lesquelles le prescripteur avait indiqué que le médicament ne devait pas être substitué compromettait l'objectif de la prescription unifiée.

Conclusions : La mise en place de la prescription unifiée n'a pas été considérée comme un succès par les pharmaciens d'officine au Liban. Des efforts doivent être consentis pour améliorer la communication avec les prescripteurs et sensibiliser le public au rôle que jouent les pharmaciens et les médicaments génériques.

$$
\begin{aligned}
& \text { آراء الصيادلة المجتمعيين في لبنان بشأن الوصفة الطبية الموحّدة: دراسة قائمة على مزيج من الأساليب }
\end{aligned}
$$

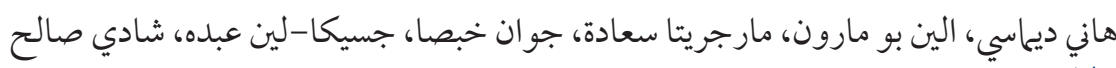

$$
\begin{aligned}
& \text { الخلاصة } \\
& \text { الخلفية: أُدخلت الوصفة الطبية الموحّدة في لبنان في عام 2011. وتَثّل أحد أهدافها في التوفير في نفقات الأدوية. }
\end{aligned}
$$

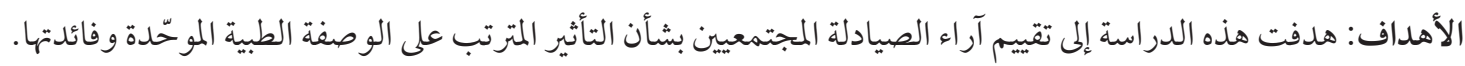

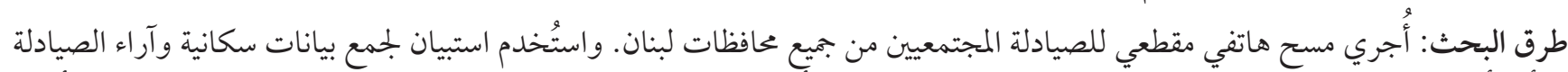

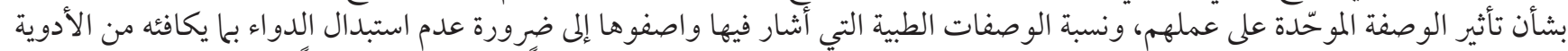

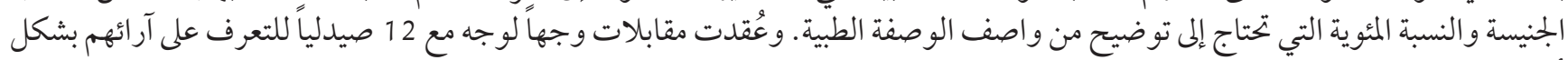

$$
\begin{aligned}
& \text { أكبر. }
\end{aligned}
$$

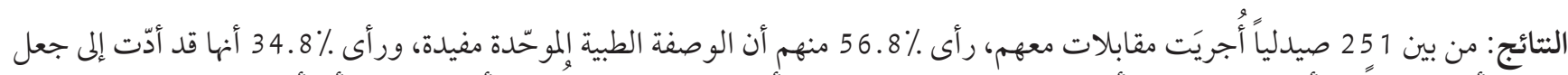

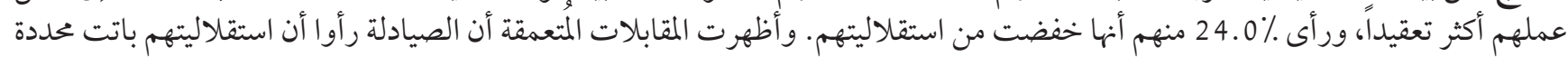

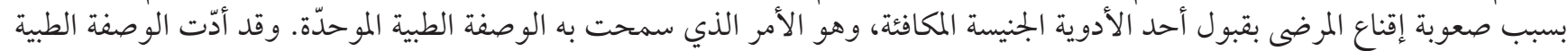

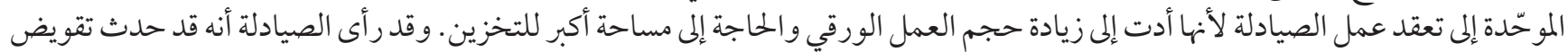

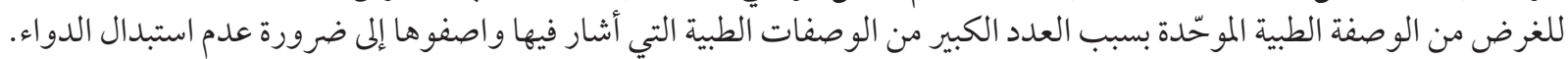

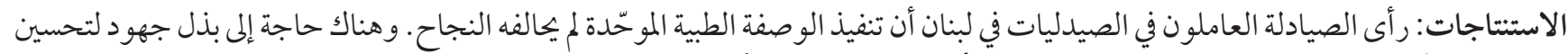

$$
\begin{aligned}
& \text { الاتصال بمُقدّمي الوصفات الطبية وتثقيف الجمهور بشأن دور الصيادلة والأدوية الجنيسة. }
\end{aligned}
$$




\section{References}

1. Brahams D. Benzodiazepine overprescribing: successful initiative in New York State. Lancet. 1990;336(8727):1372-3. http://doi. org/10.1016/0140-6736(90)92914-4

2. Korsmeyer P, Kranzler HR, editors. Encyclopedia of drugs, alcohol \& addictive behavior. 3rd edition. New York: Macmillan Reference USA; 2009.

3. Triplicate Prescription Program (TPP), Alberta. Edmonton: College of Physicians \& Surgeons of Alberta; 2012 (http://www.cpsa.ca/ tpp, accessed 6 June 2017)7.

4. Pharmaceuticals and healthcare in Lebanon: numerous opportunities to explore. Beirut: Blominvest Bank; 2016 (https://blog.bloa minvestbank.com/wp-content/uploads/2016/03/Pharmaceuticals-and-Healthcare-in-Lebanon-Numerous-Opportunities-to-Explore1.pdf, accessed 21 August 2020).

5. Pearson GJ. Evolution in the practice of pharmacy-not a revolution! CMAJ. 2007;176(9):1295-6. http://doi.org/10.1503/cmaj.070041

6. Hassali MA, Shafie AA, Jamshed S, Ibrahim MI, Awaisu A. Consumers' views on generic medicines: a review of the literature. Int J Pharm Pract. 2009;17(2):79-88. https://doi.org/10.1211/ijpp.17.02.0002

7. Manigault KR, BCACP C, Marcheva GA, Peasah SK. Insights into effective generic substitution. US Pharm. 2016;41(6):29-33.

8. Toklu HZ, Dülger GA, Hıdıroğlu S, Akici A, Yetim A, Gannemoğlu HM, et al. Knowledge and attitudes of the pharmacists, prescribers and patients towards generic drug use in Istanbul-Turkey. Pharm Prac (Granada). 2012;10(4):199-206.

9. Gill L, Helkkula A, Cobelli N, White L. How do customers and pharmacists experience generic substitution? Int J Pharm Healthc Mark. 2010;4(4):375-95. https://doi.org/10.1108/17506121011095218

10. Sanchez CK, Zurke A. Patient perceptions of generic drugs: dispelling misconceptions. Pharmacist. 2016;41:36-41.

11. Polit DF, Beck CT. Nursing research: principles and methods. 7th edition. Philadelphia. Lippincott Williams \& Wilkins; 2004.

12. IBM SPSS Statistics for Windows, version 24.0. Armonk, NY: IBM Corp; 2016.

13. Law No. 367. Practice of the profession of pharmacy. Beirut: Lebanese Republic; 1994 (https://opl.org.lb/pdf/regulations/367.pdf, accessed 1 September 2020).

14. Yousefi N, Mehralian G, Peiravian F, Noee F. Generic substitution policy implementation: A pharmacists' perspective survey. J Generic Med. 2015;12(1):17-25. https://doi.org/10.1177/1741134315608908

15. Saleh S, Samra CA, Jleilaty S, Constantin J, El Arnaout N, Dimassi H, et al. Perceptions and behaviors of patients and pharmacists towards generic drug substitution in Lebanon. Int J Clin Pharm. 2017;39(5):1101-9. https://doi.org/10.1007/s11096-017-0509-4

16. El-Jardali F, Fadlallah R, Morsi RZ, Hemadi N, Al-Gibbawi M, Haj M, et al. Pharmacists' views and reported practices in relation to a new generic drug substitution policy in Lebanon: a mixed methods study. Implement Sci. 2017;12(1):23. https://doi. org/10.1186/s13012-017-0556-1

17. Murshid MA, Mohaidin Z. Physicians' perceptions towards brand medicine and its effect on prescribing: a narrative review. J Generic Med. 2017;13(4). https://doi.org/10.1177/1741134317709509

18. El-Dahiyat F, Kayyali R, Bidgood P. Physicians' perception of generic and electronic prescribing: a descriptive study from Jordan. J Pharm Policy Pract. 2014;7(1):7. https://doi.org/10.1186/2052-3211-7-7

19. Ameri MA, Mohamed W, Makramalla E, Shalhoub B, Tucker A, Johnston A. Renal patients' views on generic prescribing and substitution: example from the United Arab Emirates. East Mediterr Health J. 2013;19(4):373-81. https://doi.org/10.26719/2013.19.4.373

20. Skipper N, Vejlin R. Determinants of generic vs. brand drug choice: evidence from population-wide Danish data. Soc Sci Med. 2015;130:204-15. https://doi.org/10.1016/j.socscimed.2015.01.013

21. Alpern JD, Stauffer WM, Kesselheim AS. High-cost generic drugs-implications for patients and policymakers. N Engl J Med. 2014;371(20):1859-62. https://doi.org/10.1056/NEJMp1408376

22. Kesselheim AS, Avorn J, Sarpatwari A. The high cost of prescription drugs in the United States: origins and prospects for reform. JAMA. 2016;316(8):858-71. https://doi.org/10.1001/jama.2016.11237

23. Arbid J. Waiting for (re) forms. Executive Magazine. 8 April 2015 (https://www.executive-magazine.com/economics-policy/healthi care-waiting-for-reforms, accessed 20 August 2020).

24. Kennedy AG, Littenberg B, Callas PW, Carney JK. Evaluation of a modified prescription form to address prescribing errors. Am J Health Syst Pharm. 2011;68(2):151-7. https://doi.org/10.2146/ajhp100063

25. Andersen S. Implementation of a new prescription system. A qualitative survey of organizational barriers. Ugeskr Laeger. 2002;164(38):4449-53. https://doi.org/10.1136/qhc.11.1.19

26. Rubak S, Andersen M-LE, Mainz J, Olesgård P, Lauritzen T. How do general practitioners, pharmacists and patients evaluate the substitution system for prescription in Denmark? Eur J Gen Pract. 2002;8(1):13-7. https://doi.org/10.3109/13814780209160823

27. García-Ramos S, Utrilla GB. Electronically assisted prescription will minimise drug transcription errors. Farm Hosp. 2011;35(2):64-9. https://doi.org/10.1016/j.farma.2010.06.002

28. Kennedy AG, Littenberg B. A modified outpatient prescription form to reduce prescription errors. Jt Comm J Qual Saf. 2004;30(9):480-7. https://doi.org/10.1016/s1549-3741(04)30056-0 
29. Drug pricing: research on savings from generic drug use. Washington, DC: United States Government Accountability Office; 2012 (https://www.gao.gov/assets/590/588064.pdf, accessed 29 August 2020).

30. Carroll NV. Do community pharmacists influence prescribing? J Am Pharm Assoc. 2003;43(5):612-21. https://doi. org/10.1331/154434503322452256 